\title{
Genetic variation for sensitivity to a thyme monoterpene in associated plant species
}

\author{
Catrine Grønberg Jensen · Bodil Kirstine Ehlers
}

Received: 4 April 2009 / Accepted: 26 October 2009 / Published online: 17 November 2009

(C) The Author(s) 2009. This article is published with open access at Springerlink.com

\begin{abstract}
Recent studies have shown that plant allelochemicals can have profound effects on the performance of associated species, such that plants with a history of coexistence with "chemical neighbour" plants perform better in their presence compared to naïve plants. This has cast new light on the complexity of plant-plant interactions and plant communities and has led to debates on whether plant communities are more co-evolved than traditionally thought. In order to determine whether plants may indeed evolve in response to other plants' allelochemicals it is crucial to determine the presence of genetic variation for performance under the influence of specific allelochemicals and show that natural selection indeed operates on this variation. We studied the effect of the monoterpene carvacrol-a dominant compound in the essential oil of Thymus pulegioides - on three associated plant species originating from sites where thyme is either present or absent. We found the presence of genetic variation in both naïve and experienced populations for performance under the influence of the allelochemical but the response varied among naïve and experienced plant. Plants from experienced populations performed better than naïve plants on carvacrol soil and contained significantly more seed families with an adaptive response to carvacrol than naïve populations. This suggests that the presence of $T$. pulegioides can act as a selective agent on associated species, by favouring
\end{abstract}

Communicated by Jeff Karron.

C. G. Jensen · B. K. Ehlers $(\bowtie)$

Department of Biological Sciences,

University of Aarhus, Ny Munkegade,

Build. 1540, 8000 Århus C, Denmark

e-mail: bodil.ehlers@biology.au.dk

C. G. Jensen

e-mail: catrine.jensen@biology.au.dk genotypes which perform best in the presence of its allelochemicals. The response to the thyme allelochemical varied from negative to neutral to positive among the species. The different responses within a species suggest that plant-plant interactions can evolve; this has implications for community dynamics and stability.

Keywords Allelochemical - Local adaptation · Plant-plant interactions · Reaction norm .

Monoterpene

\section{Introduction}

Many plant species produce secondary compounds with allelopathic effects (reviews in Rice 1979; Langenheim 1994). Some of these plants have the ability, via leaching of allelochemicals, to modify their local environment in a way that puts associated species under selective pressure to adapt to the direct as well as indirect effects of the allelochemicals. In trees, conifers are known for their high production and diversity of terpenes and phenolics which significantly modify the soil conditions (White 1991; Pavolainen et al. 1998; Prescott et al. 2000) and affect the diversity of the understory vegetation (Iason et al. 2005). Some invasive species can nearly eradicate entire native plant communities via the modifications that come about from the leaching of their allelochemicals. For instance, Centaurea maculosa and Centaurea diffusa are invasive species in North America. Both of these species leach specific allelochemicals which negatively impact the performance of other plant species and modify the local soil biota creating a positive feedback on themselves. The negative effects of the allelochemicals are much greater in North American communities compared to native Eurasian ones (e.g. Callaway 
and Aschehoug 2000; Callaway et al. 2004; see also Blair et al. 2008 for discussions on detection and stability of specific allelochemicals in soil). Prati and Bossdorf (2004) showed similar responses in their study on the allelopathic effects of the invasive plant, Alliaria petiolata. The high production of phenolic compounds in Vaccinium myrtillus differentially affects the germination and growth of two spruce species, having a more negative effect on the introduced rather than native spruce species (Mallik and Pellissier 2000). These studies demonstrate that sensitivity to specific plant allelochemicals can vary with the history of co-existence of the interacting plants.

Terpenes are the largest class of secondary compounds in plants (Langenheim 1994; Gershenzon and Dudareva 2007) and their ecological role is a key component in both antagonistic and mutualistic interactions. Their functions vary from having either inhibitory or stimulating effects on a number of associated organisms such as bacteria, fungi, other plants and herbivores (Langenheim 1994; Gershenzon and Dudareva 2007). In a community context, the role of terpenes in soil nutrient cycling may be particularly important. It is known that terpenes in the soil can alter the nitrogen cycle by inhibiting the nitrification process, thereby decreasing the amount of available nitrate in the soil, and increasing that of ammonium (White 1991; Pavolainen et al. 1998; Hättenschwiler and Vitousek 2000; Castells et al. 2003). Presence of terpenes in the soil may thereby affect the competitive interactions between plants in the community by favouring plants that are good at adjusting or adapting to the local changes in nitrogen availability.

One plant genus famous for its production of terpenes is the aromatic Thymus. The common Mediterranean species Thymus vulgaris has a genetically determined polymorphism for the production of monoterpenes constituting the main component of its essential oil. A total of at least seven different so-called chemotypes, each dominated by a different monoterpene, are known from this species (Vernet et al. 1986). Thyme populations differ with respect to chemotypes produced, and individual populations are usually dominated by one to two different types (Thompson et al. 2003). The grass Bromus erectus shows local adaptation to its home non-phenolic chemotype by germinating and growing better on soil collected under its "home" thyme chemotype compared to soil from sites where $T$. vulgaris produces a phenolic chemotype (Ehlers and Thompson 2004). Thyme species found in northern Europe also show variation in their terpene production (Sáez and Stahl-Biskup 2002). Grøndahl and Ehlers (2008) studied four different plant species originating from sites dominated by either Thymus pulegioides (producing a phenolic monoterpene), or T. serpyllum (producing sesquiterpenes) and showed that plants germinated and grew better on soil treated with their "home" terpene. Plants that showed an adaptive response to their local thyme terpene originated from sites where associated plants and thyme showed a significantly positive spatial association.

The above studies demonstrate that plant allelochemicals can act as a strong selective force driving evolution in plant-plant interactions. Fundamental for local adaptation to evolve is the presence of genetic variation for an adaptive response upon which selection can operate. So far studies of associated plant species' response to the presence of a "chemical neighbour" have focused on a "population-level" response by comparing the performance of species from different origins and history with the plant producing the allelochemical. Variation in performance and sensitivity among individual plants to a plant allelochemical has been documented (e.g. Callaway et al. 2005a). However, as far as we know, no one has yet examined the presence of genetic variation in associated species for sensitivity to specific plant allelochemicals, and asked if such variation is in accordance with selection operating on this.

In this study we looked for the presence of genetic variation for sensitivity to the thyme monoterpene carvacrol, a dominant component of the essential oil in T. pulegioides. We use maternal seed families from three different species originating from sites where they either grow together with T. pulegioides (experienced) or from sites where T. pulegioides is absent (naïve). All three study species are common in plant communities where $T$. pulegioides dominates the ground vegetation. We ask the following questions:

1. Do associated plant species show genetic variation for sensitivity to the thyme monoterpene?

2. Do experienced and naïve plants differ in their response to carvacrol?

3. Is there variation in sensitivity to the thyme monoterpene between experienced and naïve plants, which may then suggest that the presence of $T$. pulegioides in a plant community can act as a selective agent on the genetic variation in associated species?

\section{Materials and methods}

Study sites and study species

Five sites in Denmark, ranging from Eastern Jutland to the western part of Funen were chosen for this study. At two of the sites Thymus pulegioides dominates the ground cover of the vegetation and at the other sites T. pulegioides is absent. At sites with $T$. pulegioides, the essential oil of the thyme plants is dominated by the phenolic monoterpene carvacrol (Grøndahl et al. 2008). All sites are dry grassland habitat, and located in the same geographic region around the Eastern Sea. 
We chose three plant species, Plantago lanceolata L. (Plantaginaceae), Campanularotundifolia L. (Campanulaceae) and Agrostiscapillaris L. (Poaceae), common at the $T$. pulegioides sites. All three plant species are short lived, outcrossing perennials, mainly wind pollinated (Agrostis and Plantago) or insect pollinated (Campanula), with seeds dispersed by wind (Agrostis and Campanula) or animals (Plantago). Seeds were collected from sites where thyme was either a dominant component of the ground vegetation or from sites where thyme was absent. We refer to these as "experienced" and "naïve", respectively, with reference to thyme chemistry. We collected seeds from two naïve and two experienced populations of $P$. lanceolata, and from one naïve and one experienced population of both $C$. rotundifolia and A. capillaris. Seeds were collected from up to 20 different maternal plants per species per population at fruit ripening the year prior to the experiment and kept in paper bags until sowing. At the sites where T. pulegioides is present, seeds were collected from plants growing in the middle of thyme tufts. For both experienced and naïve populations, seeds were collected from maternal plants with an interplant distance of at least $2 \mathrm{~m}$ to avoid sampling of seed families from genetically identical plants.

\section{Soil preparation}

Two types of soil were prepared; soil treated with the thyme terpene carvacrol and control soil. The soil used was standard greenhouse soil (Pindstrup no. 1) with a low fertilisation level (approximately $0.078 \mathrm{~g}$ nitrogen, $0.039 \mathrm{~g}$ phosphorus and $0.13 \mathrm{~g}$ potassium $1^{-1}$ soil). Soil with a low fertilisation level was chosen to mimic the general low fertilisation level in dry grassland habitats from which the study species originated. Soil treated with carvacrol contained $50 \mu \mathrm{l}$ carvacrol $100 \mathrm{~g}^{-1}$ soil dry weight. This corresponds to approximately $500 \mu \mathrm{g} \mathrm{g}^{-1}$ and is within the range of concentration plants can experience in natural sites [230-1,500 $\mathrm{g} \mathrm{g}^{-1}$ dry weight, see Grøndahl and Ehlers (2008) for details].

The terpene was added to the soil as follows: liquid carvacrol (Sigma-Aldrich) was mixed in separate Petri dishes with filter paper; the filter paper was cut into small pieces of approximately $1 \mathrm{~cm}^{2}$ and sealed in plastic bags for $24 \mathrm{~h}$ after which all liquid had soaked into the paper; the filter papers were mixed carefully into the soil. Soil with the filter paper was then left for a further $24 \mathrm{~h}$ sealed in plastic bags to give a homogeneous terpene concentration and was afterwards transferred into individual germination pots.

\section{Experimental setup}

Seeds from each maternal plant were germinated in control and carvacrol soil. After an initial growth period the seed- lings were transferred to individual pots with the respective soil treatment.

The number of seeds and seedlings available per plant varied. In order to test for any among-family variation in response to soil treatment we chose to have a minimum of four and a maximum of eight plants/maternal plant per soil treatment. This resulted in a final set up of 12 seed families per population from the two naïve and two experienced populations of $P$. lanceolata, 17 naïve and 20 experienced seed families from $C$. rotundifolia and 20 naïve and 18 experienced seed families from A. capillaris. Individual pots were kept in a greenhouse with day temperatures reaching up to $23^{\circ} \mathrm{C}$ and night temperatures were $15^{\circ} \mathrm{C}$. Pots were randomised twice a week. After a growth period of 4 months all plants were harvested. The plants were rinsed and divided into above- and belowground parts and for Plantago and Campanula, reproductive stalks were separated from the vegetative parts (Agrostis did not flower during the course of the experiment). The number of reproductive stalks was counted and the vegetative plant material was oven dried at $50^{\circ} \mathrm{C}$ for $48 \mathrm{~h}$ and then weighed. Biomass was assessed from a total of 620 plants of $P$. lanceolata, 504 plants of $C$. rotundifolia and 550 plants of $A$. capillaris.

Statistical analysis

Mixed model ANOVA was used to analyse the effect of treatment, population, family (within population) and their interaction on biomass of Agrostis and Campanula plants, with treatment considered a fixed effect and the remaining predictor variables as random. For Plantago, as we had two experienced and two naïve populations, the mixed model ANOVA additionally included the effect of origin (either experienced or naïve with respect to thyme), population nested within origin, and family nested within population nested within origin. Residual error plots were inspected visually to verify normality. These analyses were performed using the program JMP (SAS Institute 1999).

To assess the reaction norm of the seed families from naïve and experienced populations, their respective response to treatment was analysed using a maximum likelihood method. We refer to a "positive reaction norm" when a seed family performed better on carvacrol soil than on control and a "negative reaction norm" for a seed family with the reverse response. Each population was characterised by the number of reaction norms in each category. Assuming that the proportion of positive reaction norms is binomially distributed, we tested for differences in the proportion of positive reaction norms between experienced and naïve populations using a likelihood ratio test (LRT). Significance was assessed by assuming that under the null hypothesis of equal proportions, the LRT statistic is $X^{2}$ distributed with $1 d f$. 


\section{Results}

Effect of treatments and origin on plant performance

Our results show that the effect of carvacrol depends on the origin of plants. This was demonstrated by significant population $\times$ treatment interactions for total, aboveground and root biomass of Agrostis, for aboveground biomass of Campanula and by a significant origin $\times$ treatment interaction for Plantago (Table 1).

For Agrostis (Table 1; Fig. 1a,d,g), the biomass of experienced plants was overall higher than that of naïve plants, with the largest difference between naïve and experienced plants on carvacrol soil. Moreover, naïve Agrostis plants had the lowest total and aboveground biomass on carvacrol soil, whereas experienced plants increased their total and root biomass on carvacrol soil compared to control soil (Fig. 1a,g).

Experienced Campanula plants also had significantly higher aboveground biomass than naïve plants on carvacrol soil (Fig. 1b,e), whereas no difference in biomass between experienced and naïve plants was found on control soil. While naive Campanula plants had the lowest biomass on carvacrol soil, the experienced plants performed equally well on both soil treatments. The number of spikes produced did not differ between the naïve and experienced population but varied significantly between treatments, always being lower on carvacrol soil (Table 1; Fig. 1j).

In contrast to Agrostis and Campanula plants, the biomass of both experienced and naïve Plantago was significantly lower on carvacrol soil compared to control soil

Table 1 Summary of ANOVA for biomass of Agrostis capillaris, Campanula rotundifolia, and Plantago lanceolata, and spike production of $C$. rotundifolia and $P$. lanceolata in response to origin (Ori), Thymus pulegioides present or absent, soil treatments (Trt), Population $(P o p)$ and family (Fam)

\begin{tabular}{|c|c|c|c|c|c|c|c|c|c|c|}
\hline \multirow{2}{*}{$\begin{array}{l}\text { Agrostis capillaris } \\
\text { Source }\end{array}$} & \multicolumn{3}{|c|}{$\begin{array}{l}\text { Total biomass } \\
R^{2}=0.42\end{array}$} & \multicolumn{3}{|c|}{$\begin{array}{l}\text { Aboveground biomass } \\
R^{2}=0.45\end{array}$} & \multicolumn{3}{|c|}{$\begin{array}{l}\text { Root biomass } \\
R^{2}=0.34\end{array}$} & \multirow[t]{2}{*}{$\begin{array}{l}\text { Number of } \\
\text { spikes }\end{array}$} \\
\hline & $d f$ & SS & $F$ & \multicolumn{2}{|c|}{ SS } & $F$ & SS & \multicolumn{2}{|l|}{$F$} & \\
\hline Trt & 1 & 0.11 & 0.03 & \multicolumn{2}{|c|}{17.6} & $15.02 * * *$ & 14.9 & \multicolumn{2}{|c|}{$9.31 * *$} & na \\
\hline Pop & 1 & 306.3 & $73.4 * * *$ & \multicolumn{2}{|c|}{104.3} & $89.04 * * *$ & 53.1 & \multicolumn{2}{|c|}{$33.11 * * *$} & na \\
\hline Fam (Pop) & 36 & 713.6 & $4.75 * * *$ & \multicolumn{2}{|c|}{215.0} & $5.10 * * *$ & 212.0 & \multicolumn{2}{|c|}{$3.67 * * *$} & na \\
\hline Trt $\times$ Pop & 1 & 56.4 & $13.52 * * *$ & \multicolumn{2}{|c|}{9.5} & $8.12 * *$ & 19.6 & \multicolumn{2}{|c|}{$12.21 * * *$} & na \\
\hline Trt $\times$ Fam $($ Pop $)$ & 36 & 342.7 & $2.28 * * *$ & & & $1.95 * *$ & 120.6 & & $9 * *$ & na \\
\hline Error & 462 & $1,927.9$ & & & & & 741.5 & & & na \\
\hline Campanula rotundifolia & & $=0.32$ & & $R^{2}=$ & & $R^{2}=0.2$ & & $R^{2}=$ & & \\
\hline Source & $d$ & SS & $F$ & SS & $F$ & SS & $F$ & $d f$ & SS & $F$ \\
\hline Trt & & 0.76 & $9.31 * *$ & 0.07 & $3.99 *$ & 0.35 & $10.49 * *$ & 1 & 54.01 & $9.77 * *$ \\
\hline Pop & & 0.46 & $5.68 *$ & 0.03 & 1.54 & 0.26 & $7.72 * *$ & 1 & 7.06 & 1.28 \\
\hline Fam (Pop) & & 9.36 & $3.30 * * *$ & 2.37 & $3.65 * * *$ & 2.69 & $2.30 * * *$ & 35 & 0.92 & 5.37 \\
\hline Trt $\times$ Pop & & 0.26 & 3.18 & 0.13 & $7.18 * *$ & 0.02 & 0.69 & 1 & 0.12 & 0.02 \\
\hline Trt $\times$ Fam $($ Pop $)$ & & 3.96 & 1.39 & 0.78 & 1.19 & 1.58 & 1.35 & 35 & 224.69 & 1.16 \\
\hline Error & & 32.52 & & 7.47 & & 13.45 & & 289 & $1,596.22$ & \\
\hline Plantago lanceolata & $R^{2}=$ & & & $R^{2}=0$. & & $R^{2}=0.39$ & & $R^{2}=$ & & \\
\hline Source & $d f$ & SS & $F$ & SS & $F$ & SS & $F$ & $d f$ & SS & $F$ \\
\hline Trt & 1 & 290.06 & $128.1 * * *$ & 56.11 & $96.41 * * *$ & 87.56 & $99.89 * * *$ & 1 & 43.41 & $5.92 *$ \\
\hline Ori & 1 & 8.27 & 3.64 & 9.32 & $16.01 * * *$ & 0.001 & 0.002 & 1 & 694.79 & $94.95 * * *$ \\
\hline Pop (Ori) & 2 & 192.89 & $42.61 * * *$ & 36.91 & $31.71 * * *$ & 64.09 & $36.56 * * *$ & 2 & 911.40 & $62.19 * *$ \\
\hline Trt $\times$ Ori & 1 & 5.27 & 2.33 & 4.11 & $7.07 * *$ & 0.23 & 0.26 & 1 & 22.76 & 3.11 \\
\hline Trt $\times$ Pop (Ori) & 2 & 4.60 & 1.02 & 0.49 & 0.42 & 4.53 & 2.58 & 2 & 4.05 & 0.28 \\
\hline Fam (Pop, Ori) & 44 & 118.19 & 1.19 & 37.30 & $1.46^{*}$ & 47.58 & 1.23 & 44 & 579.59 & $1.79 * *$ \\
\hline Trt $\times$ Fam (Pop, Ori) & 44 & 167.78 & $1.68 * *$ & 52.89 & $2.07 * * *$ & 50.90 & $1.32 *$ & 44 & 505.53 & $1.56^{*}$ \\
\hline Error & 521 & $1,179.3$ & & 304.39 & & 456.68 & & 461 & $3,378.04$ & \\
\hline
\end{tabular}

$* p<0.05$

$* * p<0.01$

*** $p<0.001$ 
Fig. 1 Total, aboveground, and root biomass of Agrostis capillaris, Campanula rotundifolia, and Plantago lanceolata and numbers of spikes produces by $C$. rotundifolia and $P$. lanceolata. Plants grew on control soil (Control) and on soil treated with the Thymus pulegioides monoterpene carvacrol (Carvacrol). White bars Plant originating from naïve populations, grey bars plant originating from experienced populations

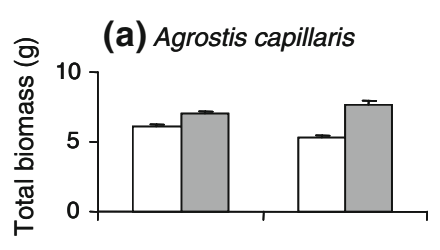

(b) Campanula rotundifolia

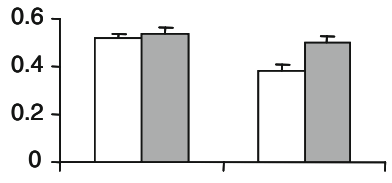

(e)
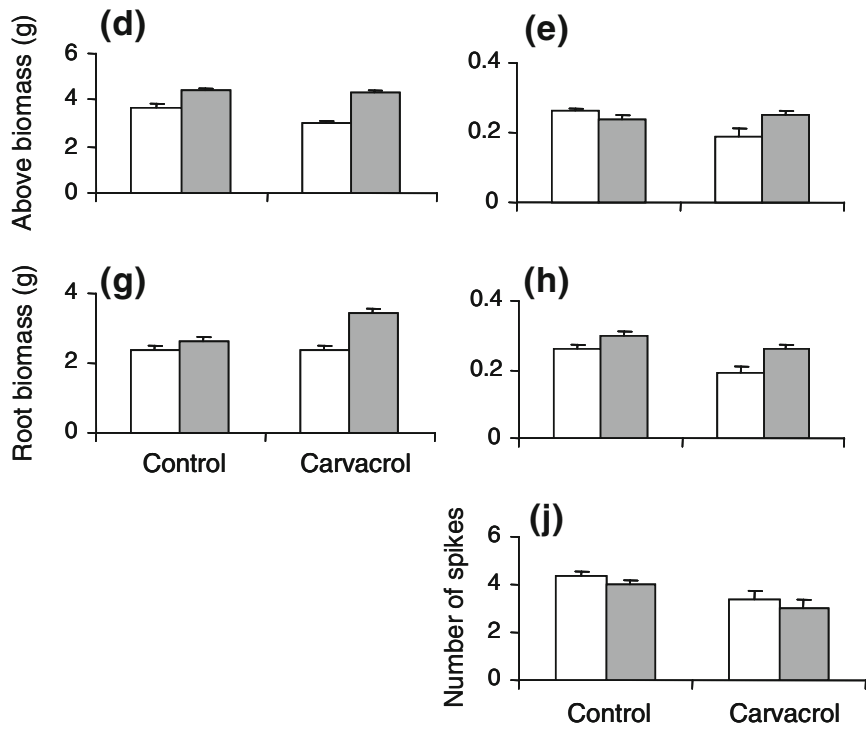

(c) Plantago lanceolata

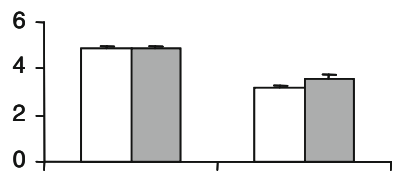

(f)

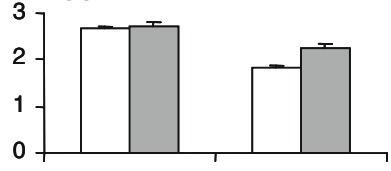

(i)
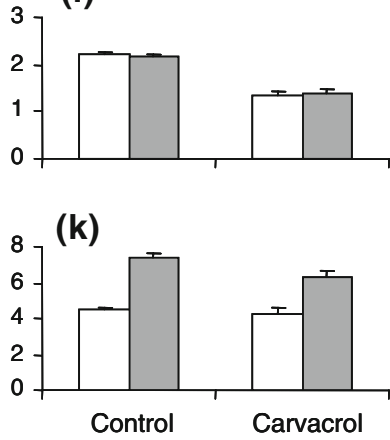

(Fig. 1c,f,i). However, a significant treatment $\times$ origin effect for aboveground biomass showed that experienced Plantago performed better on carvacrol soil than naïve Plantago, whereas no difference in aboveground biomass was found between experienced and naïve plants on control soil (Table 1; Fig. 1f). The number of spikes produced varied both with origin and populations (nested within origin; Table 1). Plantago from both experienced populations produced, overall, more spikes than plants from naïve sites (Fig. 1k). In particular, one experienced population produced almost twice as many spikes on both soil treatments as those from the other sites (data not shown).

Fig. 2 Reaction norm of individual seed families from naïve $(\mathbf{a}-\mathbf{c})$ and experienced (d-f) populations of A. capillaris, $C$. rotundifolia, and $P$. lanceolata. Experienced populations had been collected from sites with carvacrol-producing $T$. pulegioides. Each line represents the mean total biomass of plants from a seed family grown on control soil (Control) and on carvacrol soil (Carvacrol). Solid lines Positive reaction norm, dotted lines negative reaction norms
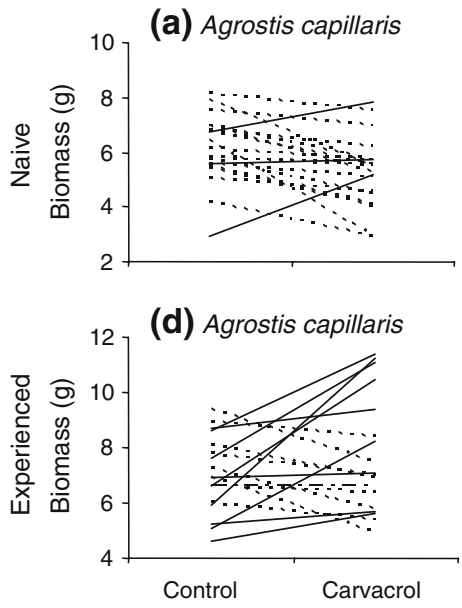

Effect of treatments and family on plant performance

The significant interactions between treatment and family (nested within population; Table 1) for the total, aboveground, and root biomass of Agrostis suggest the presence of genetic variation for sensitivity to carvacrol. Combined with the significant population $\times$ treatment interactions, these show that naïve and experienced seed families differ in their response to the thyme monoterpene. Indeed reaction norms of naïve and experienced seed families show that experienced populations harbour significantly more seed families with a positive growth response to carvacrol than naïve populations (Fig. 2; Table 2).
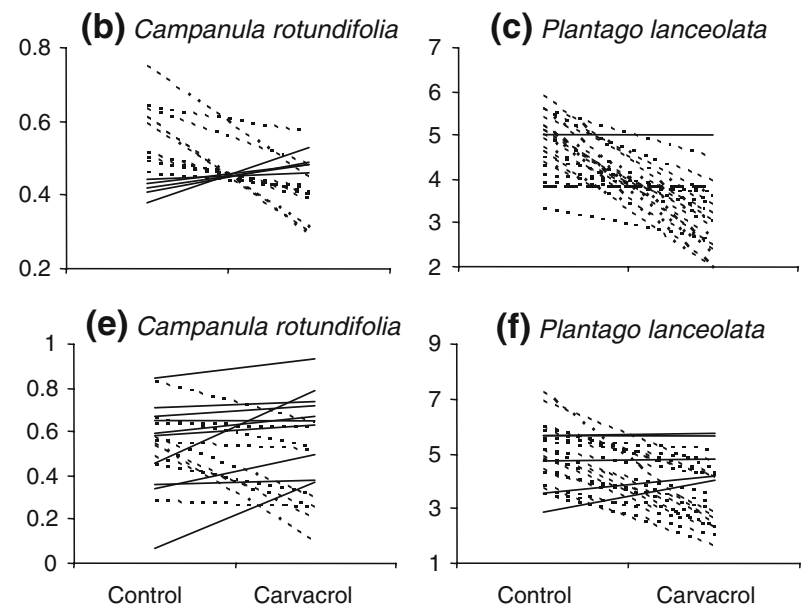
Table 2 Summary of likelihood ratio test $(L R T)$ for differences between experienced and naïve populations in proportion of seed families showing a positive growth response on carvacrol soil a LRT null hypothesis assumes equal proportions of positive reaction norms between populations. $P$-values for LRT are $\chi^{2}$ distributed with $1 d f$

\begin{tabular}{|c|c|c|c|c|c|}
\hline Species & $\begin{array}{l}\text { Naive }(\mathrm{N}) / \\
\text { Experienced (E) }\end{array}$ & $n$ & $\begin{array}{l}\text { Positive } \\
\text { reaction norm }\end{array}$ & $\begin{array}{l}\text { Negative } \\
\text { reaction norm }\end{array}$ & $\begin{array}{l}\mathrm{LRT}^{\mathrm{a}} \\
(P \text {-value })\end{array}$ \\
\hline \multicolumn{6}{|l|}{ Total biomass } \\
\hline Plantago & $\mathrm{N}$ & 24 & 1 & 23 & 4.57 \\
\hline Plantago & $\mathrm{E}$ & 24 & 6 & 18 & $(P=0.032)$ \\
\hline Campanula & $\mathrm{N}$ & 17 & 5 & 12 & 1.63 \\
\hline Campanula & $\mathrm{E}$ & 20 & 10 & 10 & $(P=0.2)$ \\
\hline Agrostis & $\mathrm{N}$ & 20 & 3 & 17 & 3.41 \\
\hline Agrostis & $\mathrm{E}$ & 18 & 9 & 9 & $(P=0.0009)$ \\
\hline Pooled & $\mathrm{N}$ & 61 & 8 & 53 & 8.6 \\
\hline Pooled & $\mathrm{E}$ & 62 & 22 & 40 & $(P=0.003)$ \\
\hline \multicolumn{6}{|c|}{ Aboveground biomass } \\
\hline Plantago & $\mathrm{N}$ & 24 & 1 & 23 & 4.57 \\
\hline Plantago & $\mathrm{E}$ & 24 & 6 & 18 & $(P=0.032)$ \\
\hline Campanula & $\mathrm{N}$ & 17 & 4 & 13 & 3.88 \\
\hline Campanula & $\mathrm{E}$ & 20 & 11 & 9 & $(P=0.048)$ \\
\hline Agrostis & $\mathrm{N}$ & 20 & 2 & 18 & 3.19 \\
\hline Agrostis & $\mathrm{E}$ & 18 & 6 & 12 & $(P=0.07)$ \\
\hline Pooled & $\mathrm{N}$ & 61 & 7 & 54 & 11.41 \\
\hline Pooled & $\mathrm{E}$ & 62 & 23 & 39 & $(P=0.0007)$ \\
\hline \multicolumn{6}{|l|}{ Root biomass } \\
\hline Plantago & $\mathrm{N}$ & 24 & 1 & 23 & 0 \\
\hline Plantago & $\mathrm{E}$ & 24 & 1 & 23 & $(P=1)$ \\
\hline Campanula & $\mathrm{N}$ & 17 & 6 & 11 & 0.1 \\
\hline Campanula & $\mathrm{E}$ & 20 & 8 & 12 & $(P=0.77)$ \\
\hline Agrostis & $\mathrm{N}$ & 20 & 9 & 11 & 7.82 \\
\hline Agrostis & $\mathrm{E}$ & 18 & 15 & 3 & $(P=0.005)$ \\
\hline Pooled & $\mathrm{N}$ & 61 & 16 & 45 & 2.19 \\
\hline Pooled & $\mathrm{E}$ & 62 & 24 & 38 & $(P=0.14)$ \\
\hline
\end{tabular}

\section{Discussion}

In this study we document genetic variation for sensitivity to the thyme monoterpene carvacrol in three different plant species. We show a clear tendency for plants experienced with $T$. pulegioides to be less affected, and in the case of Agrostis, even to be positively affected, by the thyme terpene compared to plants naïve to thyme. We find especially that Agrostis - and to a lesser extent Campanula and Plantago - show patterns of genetic variation in sensitivity to the thyme monoterpene, which suggests that selection is operating on this. For all response variables in Agrostis, for aboveground biomass in both Campanula and Plantago, and for the latter also total biomass, we find that populations experienced with thyme have significantly more seed families with a positive growth response to the thyme terpene compared to populations naïve to thyme. This finding, and the fact that we in no instance found that naïve populations exceeded experienced ones in number of seed families with a positive growth response to carvacrol, is suggestive of a "footprint" of selection in the experienced populations 
for adaptation to the effects of the monoterpene leached by their thyme neighbour.

The presence of genetic variation in response to environmental cues is necessary for the ability of populations to evolve adaptations to the local environment. While we demonstrate that associated species show genetic variation for sensitivity to a local thyme monoterpene and that this variation is suggestive of selection operating at sites where thyme is present, the sampling of only one to two experienced and naïve populations of each plant species limits our ability to generalise on the adaptation of associated plant species to thyme allelochemicals. The observed variation in response to the thyme terpene between naïve and experienced seed families could be caused by genetic differences among populations due to different site condition not related to the presence or absence of $T$. pulegioides. Even though all populations were sampled in dry grassland habitats and within the same climatic region, small-scale differences in environmental conditions and reduced migration among populations could create population genetic differentiation. However, several findings suggest that the presence of the thyme terpene carvacrol is the main reason for a differential response. First, the fact that the only difference among soil treatments is the presence/absence of carvacrol itself strongly points to the thyme terpene as the main reason for the differences found between naïve and experienced plants. Second, for both Campanula and Plantago we found no difference in biomass among naïve and experienced plants on control soil which we would expect if either maternal effects or genetic differences among populations irrespective of thyme were important for our results. Differences in biomass between experienced and naïve Campanula and Plantago were only found on carvacrol soil. Third, for Agrostis, experienced plants performed better on both types of soil treatment; however, the difference in response to carvacrol between naïve and experienced sites was strongly suggestive of an adaptation to the specific thyme terpene. Naïve Agrostis had the lowest total and aboveground biomass on carvacrol soil compared to control soil while experienced Agrostis had the highest biomass on carvacrol soil compared to control soil (Fig. 1a) —a "reciprocal" response pattern expected under local adaptation (e.g. Kawecki and Ebert 2004)

Experienced plants grow better on carvacrol soil than naïve pants; however, the response to the thyme terpene varies among species from negative (Plantago), to negative and neutral (Campanula naïve versus experienced), and from neutral to positive (naïve versus experienced Agrostis). This difference in response between naïve and experienced plants suggests that the outcome of an interaction between a plant allelochemical and its associated species can evolve.

An increasing number of studies show that plant interactions can act as drivers of local evolution, and this affects the way we view community structure and stability (e.g. review by Lortie et al. 2004 and Callaway et al. 2005b). Turkington and Harper (1979) and Martin and Harding (1981) demonstrated that competition among plant species varied among plant genotypes. The performance of individual plant species under inter-specific competition increased when competing with plant genotypes from a native site compared to competition with plant genotypes of the same species but originating from a distant site. Callaway and colleagues have shown how interactions among allelochemicals from invasive plants and associated plant species are strongly affected by the evolutionary history between plants and that the performance of plants is higher among experienced plants than plants naïve to the allelochemicals (e.g. Callaway and Aschehoug 2000; Callaway and Ridenour 2004; Callaway et al. 2005b). The present study supports these findings and highlights the importance of within-species variation in the ability to respond to biotic neighbours, for an understanding of how plant interactions evolve and how this in turn affects the stability and dynamics of plant communities.

How may thyme and its monoterpenes

affect associated plants?

Thyme can be a dominant component of the vegetation in local plant communities and its effect on associated species is thus a combination of direct interaction between thyme plants and their neighbours as well as indirect interaction via the leaching of terpenes into the local environment. In this study we specifically address the effect of a thyme neighbour by studying the impact of its monoterpene on the performance of associated plant species. Monoterpenes are known to act directly as growth inhibitors of other plant species (Langenheim 1994; Vokou et al. 2003). Indirectly they may affect the performance of other plants via their effect on soil micro-organisms. Studies on aliphatic monoterpenes from pine have shown that they can affect both the amount and availability of nitrogen in soil. The amount of available nitrogen can be reduced by the effects of monoterpenes on heterotrophic organisms increasing the immobilisation of nitrogen and reducing nitrogen mineralization (White 1994). The availability of nitrogen is affected by monoterpenes inhibiting the nitrification process creating an increase in ammonium and a decrease in nitrate (White 1994; Pavolainen et al. 1998). However, the monoterpene concentrations at which these processes are affected vary. At high concentrations $\left(>1,000 \mu \mathrm{g} \mathrm{g}^{-1}\right.$ soil) net immobilization of ammonium occurred, whereas inhibition of the nitrification process occurred at monoterpene concentrations as low as 10-125 $\mathrm{g} \mathrm{g}^{-1}$ (White 1991, 1994). Similar effects may also be caused by phenolic monoterpenes in thyme. Anal- 
ysis of soil collected under T. pulegioides plants and soil collected from the same site but where distance to a $T$. pulegiodes patch was at least $10 \mathrm{~m}$, showed that the former had a significantly higher amount of ammonium and a higher ratio of ammonium:nitrate than soil collected away from thyme (B. K. Ehlers, unpublished result). In this study we used a monoterpene concentration of $500 \mu \mathrm{g}$ $\mathrm{g}^{-1}$, i.e. within the range of what associated plants may experience under natural conditions (White 1994; Grøndahl and Ehlers 2008) and where the most likely indirect effects are the inhibition of nitrification. As nitrogen is the mineral which plants require in the largest amount (Bloom et al. 2003) and is also the nutrient which is most often limiting for plant growth in terrestrial ecosystems (Vitousek et al. 1997), the effects of monoterpenes on nitrogen cycling may be particularly important for associated plant species. Plants can absorb different sources of nitrogen but use mainly nitrate and ammonium. The assimilation of ammonium is energetically more favourable for the plant than nitrate but, unlike nitrate, ammonium cannot be stored in the plant and must be assimilated immediately (Crawford and Glass 1998). Moreover, high uptake of ammonium results in excretion of protons that acidify the rhizosphere and reduce the uptake of vital cations such as magnesium, potassium, and calcium. This effect (ammonium toxicity) varies among species. For instance, de Graaf et al. (1998) found that Arnica montana and Cirsium dissectum performed best using nitrate as their nitrogen source and had reduced survival and growth at increasing concentrations of ammonium, likely due to a decrease in cation uptake. In contrast, Calluna vulgaris grew best in soil that only contained ammonium compared to mixes of ammonium and nitrate or pure nitrate (de Graaf et al. 1998). Bloom et al. (2003) showed that Lycopersicon esculentum produced significantly heavier roots when growing with ammonium compared with nitrate as a nitrogen source, but without reduction in shoot mass, indicating that plant growth was not nutrient limited. This is similar to the response of the experienced Agrostis in the present study and could indicate a positive growth response to an increased ammonium concentration in carvacrol soil.

Terpenes of thyme may affect thyme-associated species differently depending on two things: their ability to respond and adapt to an alteration in soil nutrients, and their response and ability to adapt to the inhibiting and even toxic effects of monoterpenes on enzyme activity and biochemical processes of cells (e.g. White 1994) irrespective of their indirect effects on soil nutrients.

There is increasing interest in plant interactions as drivers of evolution in plant communities. This study adds to this field in two ways: we show that a dominant thyme monoterpene can act as a potential selective agent on asso- ciated plant species; and we demonstrate that where plants co-exist with thyme, associated plant species show genetic variation in sensitivity to this allelochemical in a way which is suggestive of selection operating.

Acknowledgments We thank J. Christiansen and F. Zec for their help in the glasshouse, and A. Sølling for help in assessing biomass. T. Bataillon and J. M. Olesen, and V. Kellermann commented on earlier versions of the manuscript. The study was financed by a grant from the Danish National Research Foundation (FNU) to B. K. E. We declare that the experiments comply with the current laws of the country in which the experiment was performed (Denmark), and that we have no conflict of interest with the organization that sponsored the research.

Open Access This article is distributed under the terms of the Creative Commons Attribution Noncommercial License which permits any noncommercial use, distribution, and reproduction in any medium, provided the original author(s) and source are credited.

\section{References}

Blair AC, Weston LA, Nissen SJ, Brunk GR, Hufbauer RA (2008) The importance of analytical techniques in allelopathy studies with the reported allelochemical catechin as an example. Biol Invasions 11:325-332

Bloom AJ, Meyerhoff PA, Taylor AR, Rost TL (2003) Root development and absorption of ammonium and nitrate from the rhizosphere. J Plant Growth Regul 21:416-431

Callaway RM, Aschehoug ET (2000) Invasive plants versus their new and old neighbors: a mechanism for exotic invasion. Science 290:104-105

Callaway RM, Ridenour WM (2004) Novel weapons: invasive success and the evolution of increased competitive ability. Front Ecol Environ 2:436-443

Callaway RM, Thelen GC, Rodriguez A, Holben WE (2004) Soil biota and exotic plant invasion. Nature 427:731-733

Callaway RM, Ridenour WM, Laboski T, Weir T, Vivanco JM (2005a) Natural selection for resistance to the allelopathic effects of invasive plants. J Ecol 93:576-583

Callaway RM, Hierro JL, Thorpe AS (2005b) Evolutionary trajectories in plant and soil microbial communities: Centaurea invasions and the geographic mosaic of coevolution. In: Sax DF, Gaines SD, Stachowicz JJ (eds) Exotic species invasions: insights into ecology, evolution and biogeography. Sinauer, Sunderland, pp 341-363

Castells E, Penuelas J, Valentine DW (2003) Influence of phenolic compound bearing species Ledum palustre on soil $\mathrm{N}$ cycling in boreal hardwood forest. Plant Soil 251:155-166

Crawford NM, Glass ADM (1998) Molecular and physiological aspects of nitrate uptake in plants. Trends Plant Sci 3:389-395

de Graaf MCC, Bobbink R, Roelofs JGM, Verbeek PJM (1998) Differential effects of ammonium and nitrate on three heathland species. Plant Ecol 135:185-196

Ehlers BK, Thompson JD (2004) Do co-occuring plant species adapt to one another? The response of Bromus erectus to the presence of different Thymus vulgaris chemotypes. Oecologia 141:511-518

Gershenzon J, Dudareva N (2007) The function of terpenes natural products in the natural world. Nature Chem Biol 3:408-414

Grøndahl E, Ehlers BK (2008) Local adaptation to biotic factors: reciprocal transplants of four species associated with aromatic Thymus pulegioides and T. serpyllum. J Ecol 96:981-992

Grøndahl E, Ehlers BK, Keefover-Ring K (2008) A new trans-sabinene hydrate chemotype detected in large thyme (Thymus pulegioides L.) growing wild in Denmark. J Ess Oil Res 20:45-47 
Hättenschwiler S, Vitousek PM (2000) The role of polyphenols in terrestrial ecosystem nutrient cycling. Trends Ecol Evol 15:238-243

Iason GR, Lennon JJ, Pakeman RJ, Thoss V, Beaton JK, Sim DA, Elston DA (2005) Does chemical composition of individual Scots pine trees determine the biodiversity of their associated ground vegetation? Ecol Lett 8:364-369

Kawecki TJ, Ebert D (2004) Conceptual issues in local adaptation. Ecol Lett 7:1225-1241

Langenheim JH (1994) Higher plant terpenoids: A phytocentric overview of their ecological roles. J Chem Ecol 20:1223-1280

Lortie CJ, Brooker RW, Choler P, Kikvidze Z, Michalet R, Pugnaire FI, Callaway RM (2004) Rethinking plant community theory. Oikos 107:433-438

Mallik AU, Pellissier F (2000) Effects of Vaccinium myrtillus on spruce regeneration: testing the notion of co-evolutionary significance of allelopathy. J Chem Ecol 26:2197-2209

Martin MM, Harding J (1981) Evidence for the evolution of competition between two species of annual plants. Evolution 35:975-987

Pavolainen L, Kitunen V, Smolander A (1998) Inhibition of nitrification in forest soil by monoterpenes. Plant Soil 205:147-154

Prati D, Bossdorf O (2004) Allelopathic inhibition of germination by Alliaria petiolata (Brassicaceae). Am J Bot 91:285-288

Prescott CE, Chappell HN, Vesterdal L (2000) Nitrogen cycling in coastal Douglas-fir forests along a gradient in soil nitrogen capital. Ecology 81:1878-1886

Rice EL (1979) Alleopathy—an update. Bot Rev 45:15-109
Sáez F, Stahl-Biskup E (2002) Essential oil polymorphism in the genus Thymus. In: Stahl-Biskup E, Sáez F (eds) Thyme: the genus Thymus. Taylor and Francis, London, pp 125-143

SAS Institute (1999) JMP users guide, 3rd edn. SAS Institute, Cary

Thompson JD, Chalchat J-C, Michet A, Linhart YB, Ehlers B (2003) Qualitative and quantitative variation in monoterpene co-occurrence and composition in the essential oil of Thymus vulgaris chemotypes. J Chem Ecol 29:869-880

Turkington R, Harper L (1979) The growth, distribution and neighbour relationships of Trifolium repens in a permanent pasture. IV. Fine-scale biotic differentiation. J Ecol 67:245-254

Vernet P, Gouyon PH, Valdeyron G (1986) Genetic control of the oil content in Thymu vulgaris L.: a case of polymorphism in a biosynthetic chain. Genetica 69:227-231

Vitousek PM, Aber JD, Howarth RW, Likens GE, Matson PA, Schindler DW, Schlesinger WH, Tilman DG (1997) Human alteration of the global nitrogen cycle: sources and consequences. Ecol Appl 7:737-750

Vokou D, Douvli P, Blionis G, Halley JM (2003) Effects of monoterpenes, acting alone or in pairs, on seed germination and subsequent seedling growth. J Chem Ecol 29:2281-2301

White CS (1991) The role of monoterpenes in soil nitrogen cycling processes in ponderosa pine. Biogeochemistry 12:42-68

White CS (1994) Monoterpenes: their effects on ecosystem nutrient cycling. J Chem Ecol 20:1381-1406 